\title{
Psycho-sexual Disorders in Clinic Diabetes mellitus Patients of a Teaching Hospital of Eastern Nepal
}

\author{
Shakya DR ${ }^{1}$, Maskey R ${ }^{2}$, Karki $\mathrm{P}^{3}$, Sharma SK ${ }^{4}$ \\ ${ }^{1}$ Professor, Department of Psychiatry, ${ }^{2}$ Additional Professor, Department of Medicine, ${ }^{3}$ Professor, \\ Department of Cardiology, ${ }^{4}$ Professor, Department of Medicine, B. P. Koirala Institute of Health \\ Sciences, Dharan, Nepal
}

\begin{abstract}
Background: Diabetes mellitus, a chronic disease, is frequently associated with sexual dysfunctions. Identification and management of these dysfunctions are important for overall wellbeing of the patient, though usually neglected. We lack data on this regard from Nepal. Objective: To estimate prevalence of psycho-sexual disorders (with emphasis on erectile dysfunction) in the patients with diabetes mellitus visiting 'Diabetes clinic' of a tertiary care teaching hospital in eastern Nepal. Method: It is a hospitalclinic based prevalence study. This study analyzed consecutive diabetes mellitus clinic patients' response to self response questionnaires 'Arizona Sexual Experience Scale' (ASEX) for over all sexual dysfunction and '5- Item Version of the International Index of Erectile Dysfunction' (IIEF-5) for erectile dysfunction. 'Diabetes mellitus' diagnosis was made based on the ADA guidelines 2010. Results: Among 100 male clinic diabetes patients, majorities were married, above age 50 years and all diagnosed as type 2 diabetes mellitus. Out of total, $48 \%$ had sexual dysfunction by the ASEX and many subjects had erectile dysfunction by the IIEF-5. Conclusion: Psychosexual dysfunctions, mainly erectile dysfunction are common among diabetic patients. Hence, assessment should include attention to sexual problems as well during management of diabetes mellitus.
\end{abstract}

Key words: ASEX, Diabetes-mellitus, erectile dysfunction, psychosexual dysfunction

\section{Introduction}

Diabetes Mellitus (DM) is one of the most common chronic diseases, with prevalence of about $2 \%{ }^{1-4}$ Sexual health of these patients, frequently forgotten has surfaced out with the passage of time $e^{5-9}$ though many patients and their family may not express in the first instance. Cultural, societal, educational and many other factors may play a role in the manifestation, expression and help seeking for these psychosexual problems. ${ }^{10}$ In Nepalese context, people may hesitate to seek help for the underlying sexual symptoms. ${ }^{11}$ Psychosexual problem, e.g. erectile dysfunction worsens 'quality of life' of these people. Hence, its timely

Correspondence Author

Prof. Dhana Ratna Sakya, Department of Psychiatry, B.P. Koirala Institute of Health Sciences, Dharan, Nepal recognition and management is important. We lack data on this aspect.

This hospital clinic based prevalence study was conducted in 'Diabetes clinic' of B. P. Koirala Institute of Health sciences (BPKIHS), Nepal in March 2011- May 2012 to detect psychosexual problems with the focus on erectile dysfunction (ED) through the use of standard instruments called the 'Arizona Sexual Experience Scale' (ASEX) and the '5- Item Version of the International Index of Erectile Dysfunction' (IIEF-5). Overarching the project would be to draw attention to this usually concealed and forgotten problem and to facilitate management at all levels through a multi-specialty clinic for these needy people.

Materials and Methods

Design: It is Institute Hospital based prevalence/ 
Sexual dysfunction in Diabetes mellitus out-patients

Jour of Diab and Endo Assoc of Nepal 2020; 4 (2): (19-23)

descriptive study conducted among diabetes mellitus patients.

Subjects: We enrolled 100 consecutive male outpatients and in-patients with diabetes mellitus coming into the contact of the investigating team during study period of March 2011- May 2012. Male outpatients and inpatients aged more than 15 years admitted through Diabetes clinic to the wards that were either previously or newly diagnosed diabetic cases in B.P.K.I.H.S., Dharan were included in the study (irrespective of marital status).

Diagnosis of diabetes mellitus was done as per the American Diabetes Association (ADA) 2010 guidelines: 12

a. Fasting venous plasma glucose $\geq 126 \mathrm{mg} / \mathrm{dl}$ (7.0 $\mathrm{mmol} / \mathrm{L}$ )

b. Two hour venous plasma glucose (post $75 \mathrm{gm}$ glucose $) \geq 200 \mathrm{mg} / \mathrm{dl}(11.1 \mathrm{mmol} / \mathrm{L})$

c. $\mathrm{HbA} 1 \mathrm{C} \geq 6.5 \%$

Subject enrolment: Male participants diagnosed with DM providing informed written consent were enrolled. Information related to their sociodemographic profiles and illnesses were collected in semi-structured proforma. Sexual dysfunctions were screened with the use of the instrument 'Arizona Sexual Experience Scale' (ASEX)13 and erectile dysfunction with the '5-Item Version of the International Index of Erectile Dysfunction' (IIEF5). 14

- Arizona Sexual Experience Scale (ASEX): This simple scale was developed by the department of Psychiatry and Psychology, University of Arizona and department of Psychiatry and behavioral sciences, Stanford University to measure 5 items identified as core elements of sexual function. These 5 items sexual drive, arousal, penile erection/ vaginal lubrication, ability to reach orgasm and satisfaction from orgasm are rated on a 6-point Likert scale ranging from 1 (hyperfunction) to 6 (hypofunction). The scale has two versions, one for males and one for females, with difference in question 3 that references penile erections versus vaginal lubrication. The scales are easy to complete and the results may be used to assess current levels of sexual dysfunction (SD) or to monitor changes in sexual dysfunction over time following clinical interventions. A total score of more than 18 on the ASEX or a score of 5 (very difficult) or greater on any one item is associated with clinical sexual dysfunction. ${ }^{13}$ It has an excellent internal consistency, reliability and validity. ${ }^{15}$ It is selfrated scale and takes about 5-10 minutes. It may be completed/ rated by the interviewer.

- '5- Item Version of the International Index of Erectile Dysfunction' (IIEF-5): An abridged, 5 -item version of the International Index of Erectile Function IIEF-5 is also known as the Sexual Health Inventory for Men (SHIM). The IIEF-5 is an excellent diagnostic test for erectile dysfunction (ED). This abbreviated questionnaire is a two-thirds reduction in the number of original IIEF items, from 15 to 5 providing a quick and reliable assessment tool. The IIEF-5 consists of Items 5, 15, 4, 2, and 7 from the IIEF. The items of IIEF-5 questionnaire have been rephrased to address the past six months of sexual activity. The sensitivity is reported as 0.98 and the specificity as 0.88 .14 It is self-rated scale and takes about $5-10$ minutes. It may be completed/ rated by the interviewer.

- Semi-structured proforma: It was designed to cover all information related to their sociodemographic profiles.

Data processing: Regular meetings and interactions were held to sort out difficulties. The coded proforma were collected at the end of the week by research staffs. On receiving proformas, the informations were entered into computer and data were analysed using 'statistical package for social studies' (SPSS 17). The output of the project provided data on the sexual dysfunction (SD) with focus on erectile dysfunction (ED). Prevalence rates were calculated as mean.

Ethical consideration: The study was initiated after the approval of the 'Ethical Review Board' of the institute (IERB Ref.- Aca. 590/067/068). Informed written consent was taken from the subjects. Strict confidentiality of information was maintained and it was utilized for the research purpose and the case management. The result was presented in institute scientific forum. 


\section{Results}

Among total enrolled 100 male subjects, all had type 2 diabetes mellitus (DM).

Ethnicity distribution of the subjects showed that the top 4 common castes according to the number of subjects in the clinic of the institute were: Upper hill, disadvantaged non-dalit Terai, relatively advantaged Janajati and disadvantaged hill Janajati (Table 1).

\section{Table 1: Caste-ethnicity Distribution of Diabetes-clinic service attenders}

\begin{tabular}{|l|c|l|c|}
\hline Ethnic groups & No./ \% & Ethnic groups & No./ \% \\
\hline Upper hill & 24 & Disadvantaged nondalit Terai & 24 \\
\hline Upper Terai & 3 & Disadvantaged hill Janajati & 20 \\
\hline Relatively advantaged Janajati & 21 & Hill dalit & 8 \\
\hline Religious minority & 0 & Disadvantaged Terai Janajati & 0 \\
\hline
\end{tabular}

Average age was 52.64 (32 minimum, 78 maximum) years. Most of the patients were above 50 of age. Most of them (50\%) came from urban, some (38\%) semi urban and less (12\%) from rural background (Figure 1).

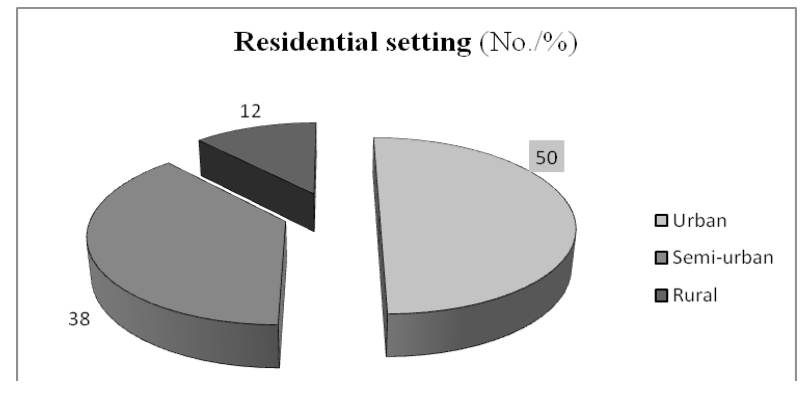

Figure 1: Residential settings

From information given by respondents, only two patients were single, rest married and 5 did not reply. As per the criteria of at least 1 item with score of 5 , overall score of 18 and 3 items with 4 scores, $48 \%$ had significant sexual dysfunction (SD) (Table 2).

Table 2: Sexual dysfunction by ASEX questionnaire

\begin{tabular}{|l|l|}
\hline Sexual dysfunction by & No./\% \\
\hline Total score 18 & 38 \\
\hline Item with score 5 & 24 \\
\hline 3 item with score 4 & 40 \\
\hline Any of the criteria & 48 \\
\hline
\end{tabular}

Only $22 \%$ denied any and $28 \%$ had only mild erectile symptom/dysfunction. About half of the subjects had moderate or severe degree of erectile dysfunction (ED).

Table 3: Erectile dysfunction among Diabetesclinic service users

\begin{tabular}{|l|c|}
\hline Grading of erectile dysfunction & $\begin{array}{c}\text { Number } \\
\text { (\%) }\end{array}$ \\
\hline No (22- 25) & 22 \\
\hline Mild (17- 21) & 29 \\
\hline Mild to Moderate (12- 16) & 31 \\
\hline Moderate (8- 11) & 14 \\
\hline Severe (5- 7) & 4 \\
\hline
\end{tabular}

\section{Discussion}

Diabetes mellitus (DM) is the most common endocrinal disorder with the prevalence of $6-7.6 \%$ in the west. ${ }^{1-3}$ The prediction of $35 \%$ increase in the worldwide prevalence of diabetes in between 1995 and 2025 and the greater rising number of people with diabetes mainly in developing countries, leading to more than 300 million globally by 2025 are alarming. ${ }^{1}$ Nepal lies in 'diabetic zone' and has been reported with the highest prevalance of pre-diabetes among the SAARC countries. ${ }^{2,3}$ A community survey in eastern Nepal showed the prevalence of $3-8 \%{ }^{4}$

The disease may lead to various complications due to affect in the small (e.g. retinopathy, nephropathy, and neuropathy) and large vessels (e.g. ischemic heart disease and stroke). A greater prevalence of psychiatric problems has been found in our institute as in other places. ${ }^{16}$ The disease has a tremendous impact on the 'quality of life'. 
Various studies done suggest that sexual dysfunctions (SD) are more common in DM (both type I and type II) than in the general population. Loss of/ reduced libido, erectile dysfunction, premature ejaculation are commonly reported among male diabetics and reduced sexual response among females. ${ }^{5}$ They may arise from a variety of vascular, neurologic, and hormonal derangements. Other factors such as psycho-social stressors and comorbidities might also play a significant role. The prevalence of these SDs may differ with a number of demographic and clinical factors such as: age, duration of DM, physical complication, control of blood sugar, BMI etc. ${ }^{6,17}$ In this study, all the cases were type II diabetes mellitus and the overall psychosexual dysfunction (SD) was found in $48 \%$ DM clinic patients by using the ASEX. We studied only among male subjects whereas females are also reported to be affected in similar fashion. ${ }^{18}$ This rate of our study coincides with an Indian study conducted in a similar DM clinic of a hospital setting using the SCID-IV and the ASEX to diagnose $\mathrm{SD} .{ }^{17}$

Erectile dysfunction (ED), one of the sexual disorders'/ dysfunctions (SD) has been reported at least 3 times more common among DM people than among general population. ${ }^{7} \mathrm{ED}$ is emerging as an important complication of diabetes in South Asians as revealed in a review by Gupta et al. ${ }^{19}$ After taking into account the confounding role of age, the prevalence of ED was found to be $37 \%$ in type II and $51 \%$ in type I DM. ${ }^{8}$ ED may also be the presenting symptom for DM and may predict later neurologic sequelae. ${ }^{9}$ Mean age in our study was above 50, i.e. 52.64 (32 minimum, 78 maximum) years. This is relatively elder than in an Ethiopian study with relatively younger age (43.39 years) showing a lower ED rate $(69.9 \%) .{ }^{20} \mathrm{ED}$ was present in many (78\%) cases in our study as found through the "5- Item Version of the International Index of Erectile Dysfunction' (IIEF-5), nearly half of the subjects had moderate or severe degree of ED and $28 \%$ had mild erectile symptom/dysfunction. This finding is consistent with an Indian study conducted with same tool the IIEF-5 in similar set up and subjects of relatively similar ages. ${ }^{21}$ This ED prevalence rate is, however higher than that reported by Kumar et al. $(58 \%)^{22}$ and the pooled prevalence in patients with DM in Africa reported by Shiferaw et al. $(71.45 \%){ }^{23}$
Since this study was conducted in a diabetes clinic of a teaching institute in a sensitive issue like sexual problem where people may not open up readily and our subjects were mainly elderly above 50 , the finding may not be generalized. Looking intensively into the underlying factors, like: age, duration of DM, physical complication, glycemic control, BMI, psychological, psychiatric, sociocultural and other factors could be undertaken in future studies for comprehensive understanding. Large sample size and intensive study is warranted for the same.

\section{Conclusion}

Nearly half of the male diabetic patients had some sexual dysfunction (SD). Many of the clinic visitors with DM had erectile symptom/ dysfunction (ED). About half of them had either moderate or severe symptoms.

\section{References}

1. International Diabetes Digest. Cambridge: FSG Communications Limited \& International Diabetes Federation, 1995; 6 (4): 87-88.

2. White F, Rafique G. Diabetes prevalence and projections in South Asia. Lancet. 2002 Sep 7; 360 (93): 804-805.

3. Mather HM, Keen H. The Southall diabetic survey, prevalence of diabetes in Asians and Europeans. BMJ. 1985: 1081-1084.

4. Sharma SK, Zou H, Togtokh A, Ene-lordache B, Carminati S, Remuzzi A et al. Burden of CKD, Proteinuria, and Cardiovascular Risk Among Chinese, Mongolian and Nepalese Participants in the International Society of Nephrology Screening Programs. American Journal of Kidney Diseases. 2010 November; 5: 915-927.

5. Lue TF, Brant W, Shindel A. Sexual dysfunction in Diabetes. Available athttp://diabetesmanager.pbworks.com/w/ page/17680308/Sexual-Dysfunction-inDiabetes.

6. Erectile Dysfunction in Patients with Diabetes Mellitus. Available at- http:// treatmenterectiledysfunction.com/erectiledysfunction-in-patients-with-diabetesmellitus/.

7. Parazzini F, Menchini Fabris F, Bortolotti A, Calabro' A, Chatenoud L, Colli E, et al. Frequency and determinants of erectile 
dysfunction in Italy. Eur Urol, 2000. 37(1): 4349.

8. Fedele D, Bortlotti A, Coscelli C, Santeusanio $\mathrm{F}$, Chatenoud L et al. Erectile dysfunction in type 1 and type 2 diabetics in Italy. International Journal of Epidemiology, 2000. 29: 524-531.

9. McCulloch DK, Young RJ, Prescott RJ, Campbell IW, Clarke BF. The natural history of impotence in diabetic men. Diabetologia. 1984 Jun; 26(6): 437-440.

10. Kalra G, Kamath R, Subramanyam A, Shah H. Psychosocial profile of male patients presenting with sexual dysfunction in a psychiatric outpatient department in Mumbai, India. Indian J Psychiatry. 2015 Jan- Mar; 57(1): 51-58.

11. Shakya DR. Dhat syndrome: Study of Clinical presentations in a Teaching Institute of Eastern Nepal. J Psychosexual health 2019: 1-6.

12. Expert committee on diagnosis and classification of Diabetes Mellitus: Diabetes Care, 2010; 33 (suppl.1): S4-S19.

13. McGahuey CA, Gelenberg AJ, Laukes CA, Moreno FA, Delgado PL, McKnight KM, Manber R. The Arizona Sexual Experience Scale (ASEX): Reliability and Validity. J Sex Marital Ther. 2000; 26(1): 25-40. DOI: 10.1080/009262300278623

14. Rosen RC, Cappelleri JC, Smith MD, Lipsky $\mathrm{J}$ and PenÄ BM. Development and evaluation of an abridged, 5-item version of the International Index of Erectile Function (IIEF5) as a diagnostic tool for erectile dysfunction. International Journal of Impotence Research. 1999; 11: 319-326.

15. Galenberg AJ, McGahuey CA, Laukes CA, Okayli G, Moreno F, Zentner L, Delgado P. Mirtazapine Substitution in SSRI-Induced Sexual Dysfunction. J Clin Psychiatry. 2000; 61(5): 356-360.

16. Shakya DR, Maskey R, Sharma SK, Karki P. Psychiatric problems in patients with diabetes mellitus attending a diabetes clinic at a tertiary care hospital in Eastern Nepal. Journal of Diabetology, 2012 June: 2-4.
17. Das R, Singh OP, Guhathakurta R, Ali SN, Mallick AK, Bhattacharya A. Prevalence and Nature of Sexual dysfunction in patients of type 2 Diabetes. Eastern Journal of Psychiatry. 2014 Jan- Jun: 31-36.

18. Fatemi SS, Taghavi SM. Evaluation of sexual function in women with type 2 diabetes mellitus. Diabetes and Vascula disease research. 2009 Jan; 6(1): 38-39.

19. Gupta R and Misra A. Epidemiology of Macrovascular Complications of Diabetes in South Asians and Comparison with Other Ethnicities. International Cardiovascular Forum Journal 2016; 8: 10-18. DOI: 10.17987/ icfj.v8i0.285.

20. SeidA, Gerensea H, Tarko S, Zenebe Y, Mezemir R. Prevalence and determinants of erectile dysfunction among diabetic patients attending in hospitals of central and north western zone of Tigray, northern Ethiopia: a cross-sectional study. BMC Endocrine Disorders. 2017; 17:16.

21. Goyal A, Singh P, Ahuja A. Prevalence and Severity of Erectile Dysfunction as Assessed by IIEF-5 in North Indian Type 2 Diabetic Males and Its Correlation with Variables. Journal of Clinical and Diagnostic Research. 2013 Dec; 7(12): 2936-2938.

22. Kumar KV, Radhakrishnan AP, Nair V, Kumar $H$. Erectile dysfunction in diabetic men. Int $\mathbf{J}$ Diabetes Dev Ctries. 2004; 24:23-26.

23. Shiferaw WS, Akalu TY, Aynalem YA. Prevalence of Erectile Dysfunction in Patients with Diabetes Mellitus and Its Association with Body Mass Index and Glycated Hemoglobin in Africa: A Systematic Review and Meta-Analysis. International Journal of Endocrinology. 2020. Available at- https://doi. org/10.1155/2020/5148370. 